\title{
Chronic Treatment with the Antidepressant Amitriptyline Prevents Impairments in Water Maze Learning in Aging Rats
}

\author{
Joyce L. W. Yau, ${ }^{1}$ June Noble, ${ }^{1}$ Carina Hibberd, ${ }^{1}$ Wayne B. Rowe, ${ }^{3}$ Michael J. Meaney, ${ }^{3}$ \\ Richard G. M. Morris, ${ }^{2}$ and Jonathan R. Seckl ${ }^{1}$ \\ ${ }^{1}$ Centre for the Study of the Ageing Brain, Molecular Medicine Centre, Western General Hospital, Edinburgh EH4 2XU, \\ United Kingdom, ${ }^{2}$ Centre for Neuroscience, University of Edinburgh, Edinburgh EH8 9LE, United Kingdom, and \\ ${ }^{3}$ Developmental Neuroendocrinology Laboratory, Douglas Hospital Research Center, McGill University, \\ Montreal H3H IR4, Canada
}

Increasing evidence links chronically elevated glucocorticoid levels and cognitive impairments in a subpopulation of aged rodents and humans. Antidepressant drugs improve hypothalamic-pituitary-adrenal axis feedback regulation and reduce plasma glucocorticoid levels. Decreasing the cumulative lifetime exposure to glucocorticoid excess by long-term exposure to antidepressants may prevent the emergence of cognitive impairments in aged rats. To test this hypothesis, we treated middle-aged male Lister hooded rats (16 months) with amitriptyline until they were 24 months of age, and their cognitive function was assessed in the water maze. Performance in the spatial learning task declined significantly with aging $(p<$ 0.01 ), with $33 \%$ of aged controls showing poorer $(<2.5 \mathrm{SD})$ probe test performance than young controls. Amitriptyline treatment from midlife preserved water maze performance with aging ( $p<0.01$ compared with aged controls) and significantly $(p<0.01)$ reduced the proportion of poor performers $(7 \%)$. Measures of anxiety-related behaviors in the elevated plusmaze were significantly $(p<0.05)$ decreased in the aged rats after amitriptyline. Furthermore, evening plasma corticosterone levels were reduced ( $30 \%$ decrease; $p<0.01$ compared with aged controls) after 6 months of amitriptyline. These data suggest that long-term treatment with amitriptyline decreases the prevalence of cognitive impairment in aged rats and that this may, in part, be a consequence of reduced plasma corticosterone levels and reduced anxiety.

Key words: corticosterone; water maze; spatial learning; amitriptyline; anxiety; glucocorticoid
Consistent evidence has revealed that approximately one-third of aging rats show an association between memory impairments, pathological changes in hippocampal neurons, and elevated blood levels of glucocorticoid hormones (corticosterone in rats, cortisol in humans) (Issa et al., 1990; Yau et al., 1995). The latter appears to be attributable to insensitivity to glucocorticoid negative feedback control of the hypothalamic-pituitary-adrenal (HPA) axis. Glucocorticoid-mediated negative feedback sensitivity is thought to be related to loss of glucocorticoid receptors (GRs) in the brain, particularly in the hippocampus (Jacobson and Sapolsky, 1991). From a mechanistic point of view, chronic glucocorticoid excess interferes with long-term potentiation as well as other putative electrophysiological processes related to learning and memory (Diamond et al., 1992; Pavlides et al., 1993); it also adversely affects hippocampal neuronal structure and eventually, perhaps, neuronal survival (Sapolsky, 1996). Glucocorticoids appear to be causal, because manipulations that keep glucocorticoid levels low throughout life prevent the emergence with age of memory impairments and hippocampal neuronal damage (Landfield et al., 1981; Meaney et al., 1988). In elderly humans, a link has also been established between elevated plasma cortisol levels, hippocampal atrophy, and the development of cognitive impair-

Received Sept. 21, 2001; revised Nov. 13, 2001; accepted Nov. 27, 2001

This study was supported by a Wellcome Trust Senior Clinical Fellowship to J.R.S., by a research development grant from the Scottish Higher Education Funding Council, and by National Institute on Aging Grant RG0-9488.

Correspondence should be addressed to Dr. Joyce L. W. Yau, Centre for the Study of the Ageing Brain, Molecular Medicine Centre, Western General Hospital, Edinburgh, EH4 2XU, UK. E-mail: joyce.yau@ed.ac.uk.

Copyright (ㄷ) 2002 Society for Neuroscience $0270-6474 / 02 / 221436-07 \$ 15.00 / 0$ ments (Lupien et al., 1998), underscoring an important clinical component of chronic glucocorticoid excess.

A critical target for manipulating blood glucocorticoid levels is GR density in brain regions involved in negative feedback control of circulating hormone levels. The hippocampus is of prominent importance, because changes in GR density in this region have been associated with altered plasma glucocorticoid levels (Meaney et al., 1989; Jacobson and Sapolsky, 1991). There are two types of receptors for glucocorticoids in the hippocampus: the mineralocorticoid receptor (MR) and the GR; both are members of the nuclear hormone receptor superfamily, and both are involved in glucocorticoid feedback (De Kloet, 1991). Recent studies have shown the key importance of monoaminergic neurotransmitters, particularly serotonin [5-hydroxytryptamine (5$\mathrm{HT}$ )] and norepinephrine (NE), in the maintenance and regulation of GR and MR expression in the hippocampus (Seckl et al., 1998). Antidepressant drugs, which alter monoaminergic neurotransmission, increase hippocampal GR and MR expression (Seckl and Fink, 1992) and indeed normalize HPA function in depression, even before clinical improvement occurs (Holsboer and Barden, 1996). We have shown that antidepressants decrease glucocorticoid levels and improve HPA feedback control in aged, cognitively impaired rats (Yau et al., 1995; Rowe et al., 1997).

In our previous studies, however, although administration of the tricyclic antidepressant amitriptyline for 2 months facilitated hippocampal (spatial) learning and memory in young rats, this treatment failed to improve memory or prevent deficits in cognition in already aged (24- to 26-month-old) rats (Yau et al., 1995). This lack of efficacy might have been attributable to a loss of 
plasticity of an already subtly impaired brain. In the present study, we treated rats with amitriptyline for 8 months from middle age (16 months) and tested their performance in a spatial learning water maze task after 2 months of treatment (to compare with our previous work) and after 8 months of treatment when the rats were 24 months of age. Anxiety-like behaviors were also assessed in the elevated plus-maze at 24 months.

\section{MATERIALS AND METHODS}

Animals. Male Lister hooded rats (Charles River, Kent, UK) were obtained at 3 months of age and maintained undisturbed before commencing the study. Rats were housed three per cage under conditions of controlled lighting (lights on from 7:00 A.M. to 7:00 P.M.) and temperature $\left(22^{\circ} \mathrm{C}\right)$, with access to food (Clark's rodents maintenance diet cubed; Special Diet Services, Essex, UK) and tap water ad libitum. Animals with overt signs of respiratory distress, infection, or tumors were excluded. All procedures were performed in strict accordance with the United Kingdom Animals (Scientific Procedures) Act.

Antidepressant drug administration. Rats were 16 months of age when randomly assigned to oral treatment with amitriptyline (Sigma, St. Louis, MO) via their drinking water for 8 months. Controls received tap water. Drinking bottles were light-protected, and solutions were renewed on alternate days. Drug intake and animal weight were monitored on a weekly basis. Control rats drank $26.8 \pm 0.3 \mathrm{ml} / \mathrm{d}$, and amitriptylinetreated rats drank $23 \pm 0.6 \mathrm{ml} / \mathrm{d}$. The average dose of amitriptyline consumed was $8.2 \pm 0.2 \mathrm{mg} \cdot \mathrm{kg}^{-1} \cdot \mathrm{d}^{-1}$, which is comparable with previously reported doses that alter HPA axis function (Reul et al., 1993; Yau et al., 1995).

Behavioral testing. The spatial memory performances of the aged rats were assessed in the water maze after 2 months and finally after 8 months of amitriptyline treatment. Young controls ( 6 months of age) were also tested in the water maze twice, 2 months apart, for comparison.

Rats were trained in a $1.8-\mathrm{m}$-diameter open-field water maze filled with water $\left(26^{\circ} \mathrm{C}\right)$ and made opaque with latex liquid (Yau et al., 1995). Prominent extra-maze visual cues around the room remained in fixed positions throughout the experiment. During behavioral testing, animals were required to locate a hidden submerged platform $10 \mathrm{~cm}$ in diameter $(1.5 \mathrm{~cm}$ below the surface), which remained in the same position across trials for individual animals but was counterbalanced across animals. Four equally spaced points (north, south, east, and west) around the edge of the pool were used as starting positions. The animals were given four trials per day for $4 \mathrm{~d}$. Trials began with the rat placed in the pool facing the side wall at a start position and ended once the animal had found the platform; if the rat had not found the platform within $120 \mathrm{sec}$, it was guided there by hand. After a period of $30 \mathrm{sec}$ on the platform, the rat was immediately re-placed in the pool at a different start position for the next trial. The latency and swim paths of the rats were monitored by a video camera mounted in the ceiling and by a computerized tracking system [HVS image analyzer (HVS Image, Hampton, UK) and Acorn Archimedes computer (Acorn Computer Group, Cambridge, UK)]. On day 5 , rats were given a retention (probe) test. For this, the platform was removed, and the swim path and time spent in the platform ("training") quadrant were recorded over $60 \mathrm{sec}$.

Elevated plus-maze. The elevated plus-maze (Panlab, Barcelona, Spain) was a cross-shaped platform made of black plastic. The apparatus consisted of two opposing open arms $(50 \times 10 \mathrm{~cm})$ and two arms of the same size but enclosed by walls $40 \mathrm{~cm}$ high. A central area of $10 \mathrm{~cm}^{2}$ connected all four arms. The maze was elevated $64 \mathrm{~cm}$ from the floor. At the start of the test, a rat was placed in the central area facing one of the open arms and allowed to explore the maze freely for $5 \mathrm{~min}$. During this period, the number of open-arm and closed-arm entries and the time spent on open arms and closed arms were measured. The apparatus was wiped clean with ethanol between rats.

Blood sampling. Blood samples $(<300 \mu \mathrm{l})$ for determination of basal plasma corticosterone levels were taken within $30 \mathrm{sec}$ of a tail nick at $1 \mathrm{hr}$ into the light (8:00 A.M., morning sample) or dark (8:00 P.M., evening sample) phase. To avoid multiple sampling in any one animal, tail-nick blood sampling from an equal number of rats randomly selected from each group was performed either 3 or 6 months after antidepressant treatment had been initiated. Blood samples were taken into EDTAcoated Eppendorf tubes, placed on ice, centrifuged, and stored at $-20^{\circ} \mathrm{C}$. Plasma corticosterone levels were measured by a previously described radioimmunoassay (A1 Dujaili et al., 1981), modified for microtiter plate

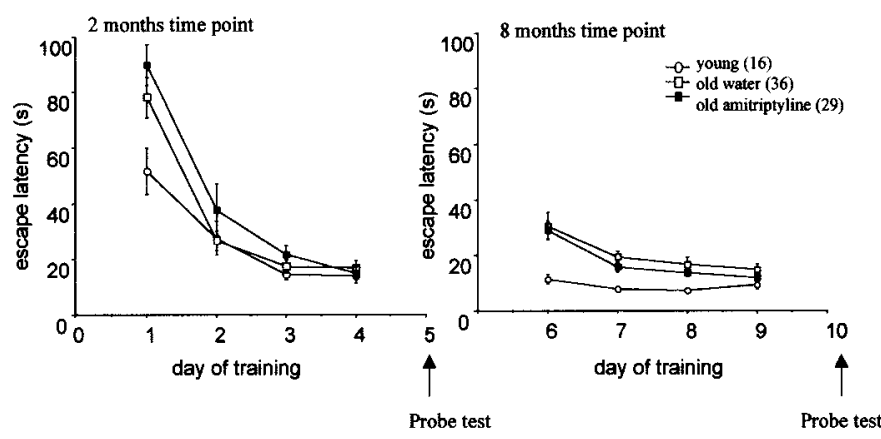

Figure 1. Water maze performance to find a hidden platform across days during the acquisition stage initially after 2 months of amitriptyline treatment and then again 6 months later after 8 months of amitriptyline treatment. Probe tests were given on days 5 and 10 of testing. Young controls at 6 months of age were included for comparison. Values are the mean \pm SEM of the mean escape latency of four trials per day. Numbers of rats are in parentheses.

scintillation proximity assay (Amersham Biosciences, Little Chalfont, UK) with a highly specific antiserum (Dr. C. Kenyon, Edinburgh University) and $\left[{ }^{3} \mathrm{H}\right]$ corticosterone (Amersham Biosciences). The intraassay and interassay coefficients of variation were $9.4 \%$ and $9.2 \%$, respectively.

Statistical analysis. Only data from rats that completed the full experimental protocol were assessed. Data were assessed by ANOVA followed by the Scheffé post hoc test. Frequency distribution was assessed by the $\chi^{2}$ test. Significance was set at a value of $p<0.05$. Values are means \pm SEM.

\section{RESULTS}

\section{Antidepressant effects on cognitive performance}

The aged rats were tested in the water maze initially at 18 months of age after 2 months of amitriptyline treatment and again at 24 months of age after 8 months of amitriptyline. All young and 18-month-old rats were able to learn the hidden-platform task efficiently, showing a decrease in escape latency with days of training (young, $F_{(11,36)}=12.0$; aged controls, $F_{(22,69)}=49.4$; aged amitriptyline-treated, $F_{(10,33)}=37.0$; all $\left.p<0.001\right)$ (Fig. 1). Young rats ( 6 months of age) showed a lower mean escape latency on the first day of training than aged rats $(p<0.05)$ but did not differ on the other days of training; all groups achieved a similar escape nadir ( $<20 \mathrm{sec}$ ) after $4 \mathrm{~d}$ of training (Fig. 1). At 18 months of age, amitriptyline treatment for 2 months had no effect on mean escape latency. Young rats given amitriptyline show improved spatial memory retention as measured in the "probe test" (percentage of time spent in the training quadrant) but not improved acquisition, as determined by escape latency (Yau et al., 1995). However, probe test times in 18-month-old rats after 2 months of amitriptyline treatment were similar to both watertreated 18-month-old and young controls (young 6-month-old controls, $41.6 \pm 4 \%$; 18-month-old controls, $42.9 \pm 2.0 \%$; 18 month-old amitriptyline-treated, $46.2 \pm 2.6 \%$ ).

When the rats were 24 months of age (after 8 months of amitriptyline or water alone), they were retested in the water maze together with the young controls ( 8 months of age). The aged rats continued to show learning, with a decrease in mean escape latency across the first $2 \mathrm{~d}$ of training (water controls, $F_{(34,105)}=6.57, p<0.001$; amitriptyline-treated, $F_{(28,87)}=14$, $p<0.001)$. Indeed, the mean escape latency on the last day of training was not significantly different from that of the young controls. Amitriptyline did not significantly alter the overall escape latency in the aged rats compared with aged controls $(p=$ 0.2) (Fig. 1). The average swim speeds were comparable for both 

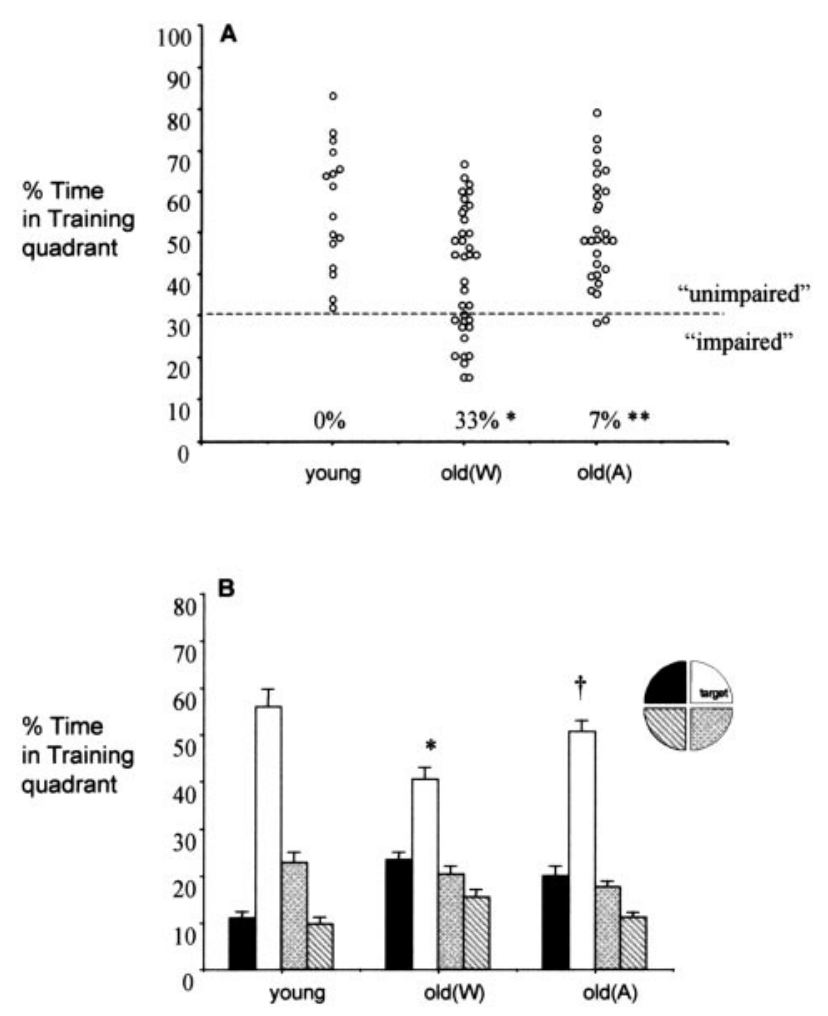

Figure 2. A, Learning performance of individual rats expressed as percentage of time spent in the training (target) quadrant during the final probe test after 8 months of amitriptyline treatment. Rats were classed with impaired performance if their probe test times were $<31 \%(25 \%$ represents chance). Using the $\chi^{2}$ test to assess the distribution of performances, there were fewer impaired rats in the amitriptyline-treated group $\left(7 \%,{ }^{* *} p<0.01\right.$ compared with aged vehicle controls; $33 \%,{ }^{*} p<0.05$ compared with young). The dashed line represents performance at the $31 \%$ probe test time level; any performances below this level were classified as cognitively impaired. $B$, Final probe test after 8 months of amitriptyline treatment showing the mean \pm SEM percentage of time spent in the different quadrants. The young controls were 8 months of age; aged rats were 24 months of age. ${ }^{*} p<0.01$ compared with young controls. ${ }^{\dagger} p<0.01$ compared with aged controls. old $(W)$, Water-treated aged controls; old $(A)$, amitriptyline-treated aged rats.

aged rat treatment groups (controls, $19 \pm 0.5 \mathrm{~cm} / \mathrm{sec}$; amitriptyline, $19 \pm 0.8 \mathrm{~cm} / \mathrm{sec}$ ), whereas the young control rats were significantly faster $(24 \pm 0.6 \mathrm{~cm} / \mathrm{sec} ; p<0.001$ compared with aged controls).

Decreased escape latencies across a series of training trials are not necessarily an indication of spatial learning, because these measures do not provide information about search strategy (Gallagher et al., 1993). For example, some aged rats use a circling strategy, which is less efficient than learning the position of the platform but can support a better escape latency performance than a random search. Therefore, we used probe test percentage times, which are also less dependent on swim speed, to rank the final water maze learning performances of the aged rats. The probe test performances in the aged rats showed a large variation (Fig. $2 A$ ), but the overall pattern was that cognitive function decreased with aging (28\% decrease in probe test time in training quadrant; $p<0.01$ compared with young controls) (Fig. 2B). Note that the aged cognitively impaired rats showed $8.6 \pm 2.2 \%$ thigmotaxic behavior (percentage of time spent near side walls), similar to that of the aged cognitively unimpaired rats $(10.4 \pm$ $2.3 \%)$.

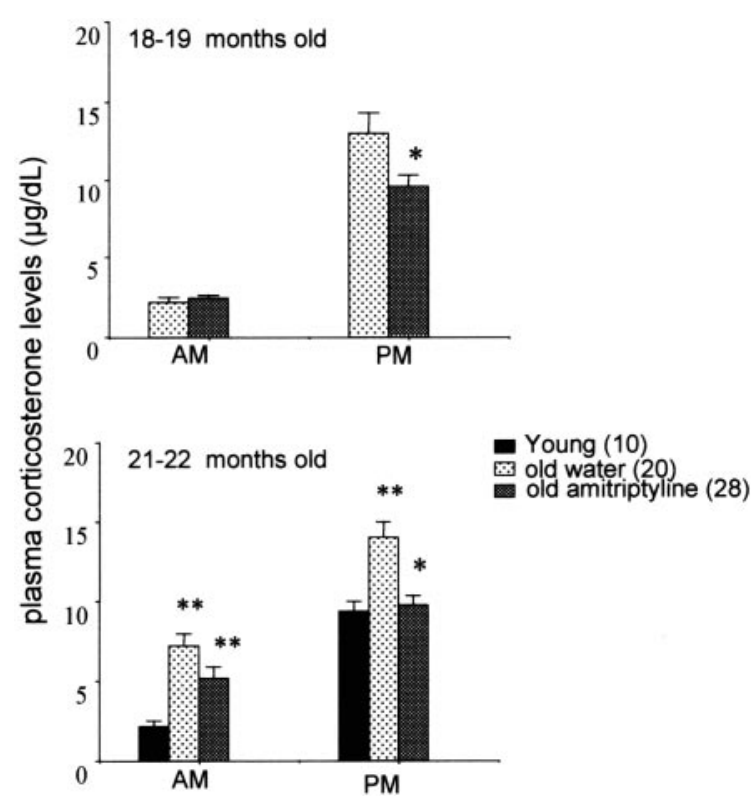

Figure 3. Plasma corticosterone levels in rats at 8.00 A.M. (morning trough) and 8.00 P.M. (evening peak) of the circadian cycle during antidepressant treatment. Rats were 19 and 22 months of age after 3 and 6 months of antidepressant treatment, respectively. Plasma corticosterone levels from young control rats 6 months of age were included for comparison. ${ }^{*} p<0.01$ compared with aged control rats. ${ }^{* *} p<0.05$ compared with young control rats. Numbers of rats with blood sampled are given in parentheses.

All of the aged rats were ranked according to their final probe test times and classed as poor performers if probe times were $<31 \%$, which is $2.5 \mathrm{SD}$ below the mean for a large cohort of young rats in this task in our water maze $(25 \%$ represents chance). Note that all of the contemporaneous young animals performed within this limit in this study. The proportion of poor performers among aged rats was 33\% in controls and $7 \%$ in amitriptyline-treated rats $(p<0.01)$ (Fig. $2 A)$. The aged cognitively impaired control rats (probe test percentage times of $<31 \%$ ) had swim speeds similar to those of the aged cognitively unimpaired rats (swim speeds: impaired, $19.3 \pm 0.8 \mathrm{~cm} / \mathrm{sec}$; unimpaired, $18.5 \pm 0.6 \mathrm{~cm} / \mathrm{sec}$ ), suggesting that sensorimotor differences do not underpin the variation with aging. Amitriptyline treatment significantly altered the distribution of water maze learning abilities in the aged rats, such that the overall performance (probe test time) was improved compared with aged controls $(25 \%$ increase; $p<0.01)$ but did not differ significantly from that of young controls (Fig. $2 A, B$ ). This was not a survival effect, because there were equal numbers of age-related deaths in each group (controls, 34\%; amitriptyline-treated rats, 35\%).

\section{Corticosterone levels and adrenal weights}

Plasma corticosterone levels at 21 months of age (water controls) were significantly higher than those of young controls during both the morning $(p<0.01)$ and evening $(p<0.001)$ phases of the diurnal cycle (Fig. 3). This was reflected in the adrenal weights, which were significantly increased $(p<0.01)$ in the aged rats compared with young controls (Table 1). Amitriptyline treatment decreased the adrenal weights $(p<0.05)$ but had no effect on body weight (Table 1). Plasma corticosterone levels were not significantly altered during the morning phase of the cycle after 3 or 6 months of amitriptyline treatment (Fig. 3). However, amitriptyline significantly decreased corticosterone levels during the 
Table 1. Adrenal weight expressed as absolute weight of both adrenals and relative to body weight in the antidepressant- and vehicle (water)treated 24-month-old rats

\begin{tabular}{llll} 
& $\begin{array}{l}\text { Adrenal } \\
\text { weight }(\mathrm{mg})\end{array}$ & $\begin{array}{l}\text { Body } \\
\text { weight }(\mathrm{gm})\end{array}$ & $\begin{array}{l}\text { Adrenal weight/ } \\
\text { body weight } \\
(\mathrm{mg} / \mathrm{gm})\end{array}$ \\
\hline Vehicle (water) (32) & $80.6 \pm 2.9^{*}$ & $523 \pm 12$ & $0.16 \pm 0.01^{*}$ \\
Amitriptyline (26) & $70.7 \pm 3.0^{* \dagger}$ & $507 \pm 15$ & $0.14 \pm 0.01^{*}$ \\
Young controls (15) & $53.2 \pm 4.2$ & $504 \pm 12$ & $0.10 \pm 0.01$
\end{tabular}

The numbers of rats per group are in parentheses. ${ }^{*} p<0.01$ compared with young controls; $\dagger p<0.05$ compared with aged controls. Values are means \pm SEM.

evening phase of the cycle after 3 months of treatment $(26 \%$ decrease; $p<0.01$ compared with vehicle controls), and this was maintained after 6 months of treatment $(30 \%$ decrease; $p<0.01)$ (Fig. 3).

\section{Elevated plus-maze}

There was no effect of age or amitriptyline treatment on locomotion on the elevated plus-maze [number of open $\left(F_{(2,28)}=2.7\right.$; $p=0.08)$ and closed $\left(F_{(2,28)}=0.6 ; p=0.6\right)$ arm entries]. Amitriptyline significantly reduced "anxiety-associated" behaviors in the aged rats [increased time spent in the open arms $(103 \%$ increase; $p<0.01$ compared with aged controls), decreased time spent in the closed arm (51\% decrease; $p<0.05$ compared with aged controls), and increased percentage of time spent in the open arms (82\% increase; $F_{(2,28)}=3.9 ; p<0.05$ compared with aged controls)] (Fig. 4). Age itself had no significant effect on the percentage of time spent on the open arms $(p=0.13$ compared with young controls).

\section{DISCUSSION}

The present study suggests that the use of antidepressants may serve as a useful therapeutic approach in attempting to ameliorate the occurrence of cognitive impairments among populations of aged individuals (Meaney et al., 1988; Yau et al., 1995; Rowe et al., 1997). An intervention paradigm such as chronic administration of amitriptyline starting at midlife resulted in an overall improvement in water maze performance and a significant reduction in the proportion of animals that normally would have shown memory deficits at 24 months of age. This amitriptyline treatment regimen also lowered plasma corticosterone levels and reduced anxiety-related behaviors in the aged rats, suggesting a more generalized improvement both in stress-related hormone levels and in behavior.

\section{Chronic amitriptyline treatment reduces evening corticosterone levels and preserves spatial memory in aged rats}

Previous cross-sectional studies have suggested that elevated corticosterone levels occur in $\sim 30 \%$ of aged rats (Issa et al., 1990; Yau et al., 1995; Rowe et al., 1997). Such animals are more likely to exhibit cognitive impairments in the water maze task, whereas aged rats with lower plasma corticosterone levels typically show normal spatial learning. In fact, individual spatial memory performance in aged rats correlates negatively with contemporaneous basal plasma corticosterone levels (Yau et al., 1995). It may be argued that when treatment was started, the distribution of performance of the rats in the treatment groups may not have been equal. However, when morning and evening blood samples were tested at 19 months of age, plasma corticosterone levels were not significantly different from those of young controls. Moreover, spatial learning did not differ at 14 months of age compared with young controls (J. L. W. Yau and J. R. Seckl, unpublished observations), nor did it differ when rats were tested 2 months after commencement of amitriptyline treatment at 18 months in the present study. Therefore, all of the aged rats appeared to be cognitively intact at the onset of treatment. In the aged controls, plasma corticosterone levels became significantly elevated (in the morning and in the evening) only later in life, at 22 months of age, consistent with previous studies (Yau et al., 1995; Rowe et al., 1997).

The lack of effect of amitriptyline on spatial memory performance after 2 months of treatment is in contrast to our previous finding that 2 months of amitriptyline treatment improved spatial memory in young rats (Yau et al., 1995). This discrepancy may be partly a result of the different route of drug administration (Yau et al., 1995) and/or the different ages of the rats at the start of treatment. The latter is an intriguing alternative, because it would imply that the cognitive plasticity to amitriptyline seen in young rats can also occur in middle-aged animals, but perhaps with a slower onset. Consistent with our previous study (Yau et al., 1995), evening corticosterone levels were selectively decreased
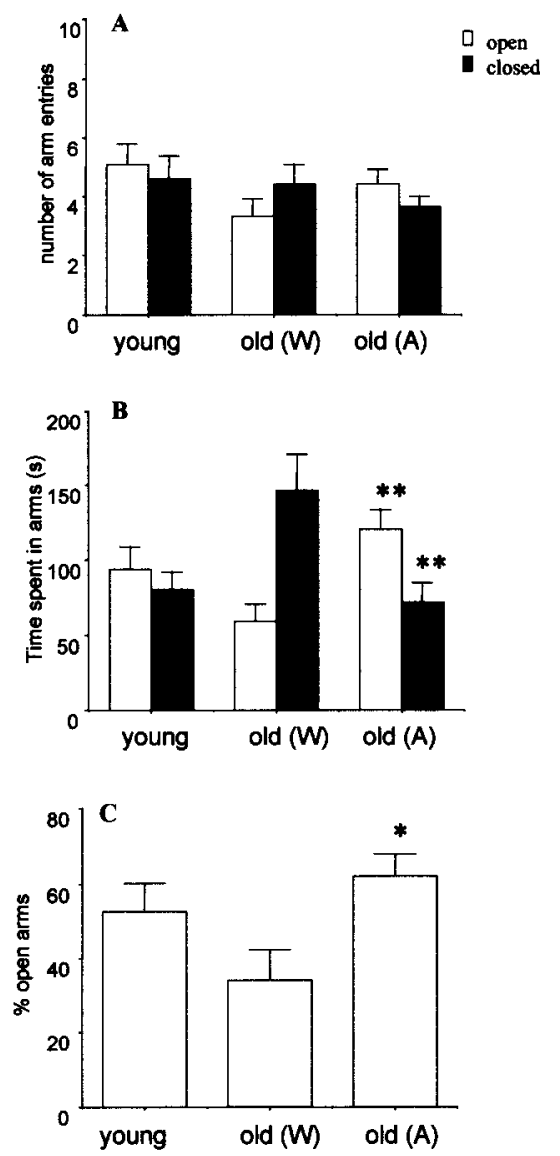

Figure 4. Effects of aging with or without amitriptyline administration from middle age for 8 months on behavior in the elevated plus-maze compared with young (6-month-old) controls. $A$, The number of entries to open and closed arms was not significantly different between the groups. $B$, The time spent in the open and closed arms differed ${ }^{* *} p<0.05$ compared with aged controls) after amitriptyline treatment. $C$, The percentage of time spent in the open arms [open/(open + closed)] was increased after amitriptyline treatment; ${ }^{*} p<0.05$ compared with aged controls. old $(W)$, Water-treated aged 24-month-old controls; old $(A)$, amitriptyline-treated aged rats. Values are mean \pm SEM. 
after 3 months of amitriptyline treatment, and this decrease was maintained after 6 months of treatment. This suggests that chronic amitriptyline treatment lowers HPA activity. The unaltered basal HPA axis activity during the morning is consistent with some (Reul et al., 1994; Yau et al., 1995; Rowe et al., 1997) but not other (Reul et al., 1993) studies and may reflect differences among studies related to age, treatment duration, route of administration, or strain. A plausible explanation for the lack of a morning effect may arise from the finding that the evening phase, or active phase of the diurnal rhythm, is believed to be the period of enhanced brain drive, whereas the morning corticosterone release may result from peripheral sources (Dallman et al., 1987). Animals treated with corticotropin-releasing hormone $(\mathrm{CRH})$ antisera exhibit an attenuated evening peak in ACTH levels, whereas morning levels remained undisturbed (Carnes et al., 1989, 1990). This latter finding suggests that the source of the morning signal is not necessarily dependent on a CRH signal; however, central $\mathrm{CRH}$ is required for the evening rise in plasma corticosterone levels.

\section{HPA axis feedback, corticosterone levels, and spatial memory}

In cognitively impaired aged rats, stress-induced rises in plasma corticosterone levels take longer to fall back to baseline than in cognitively unimpaired aged rats or young rats, suggesting defects in CNS feedback sensitivity (Issa et al., 1990). Middle-aged rats treated with stress levels of corticosterone for 3 months showed impaired learning in the water maze (Bodnoff et al., 1995). In contrast, the performance of rats in the water maze was improved by administration of corticosterone immediately after training (Sandi et al., 1997). Therefore, it appears that in certain circumstances, a transient increase in plasma corticosterone levels induced by training may facilitate memory processing (Sandi et al., 1997), but that longer durations or chronically elevated corticosterone levels often associated with aging (and reflecting poor HPA-negative feedback regulation) (Issa et al., 1990) may impair memory (Bodnoff et al., 1995). The present results suggest that amitriptyline improves glucocorticoid negative feedback efficacy in aged rats, as reflected in the reduced evening corticosterone levels. This is consistent with our previous finding, in which chronic desipramine treatment enhanced glucocorticoid-induced negative feedback efficacy and restored basal plasma corticosterone levels in aged cognitively impaired rats (Rowe et al., 1997). An enhanced glucocorticoid negative feedback efficacy may suppress water maze training-induced increases in plasma corticosterone levels more efficiently, such that plasma corticosterone levels do not remain high for longer than necessary to facilitate memory.

Interestingly, chronic amitriptyline treatment altered a specific aspect of water maze learning in the aged rats. The escape latency to find the hidden platform, thought to reflect the consolidation of spatial information via GRs (Oitzl and de Kloet, 1992), was unchanged. Furthermore, aged controls and amitriptyline-treated aged rats both had approximately equivalent declines in performance over the 6 month interval from initial testing in the water maze. This suggests that long-term memory does not appear to be preserved by amitriptyline treatment. In contrast, the searchescape strategies during the probe trial, thought to be more reflective of the actions of the MR (Oitzl and de Kloet, 1992), were enhanced in amitriptyline-treated aged rats. Together, this suggests that amitriptyline treatment may induce changes in hippocampal MR to alter the probe test times without affecting escape latencies. Previous studies have indeed shown that antidepressants, including amitriptyline, induce a more prominent effect on increasing hippocampal MR than GR expression and that the magnitude of this increase is dependent on treatment duration (Reul et al., 1993, 1994; Yau et al., 1995). Moreover, several studies suggest that it is the MR in the hippocampus (rather than the GR) that shows the more robust decline with aging (van Eekelen et al., 1991; Rothuizen et al., 1993; Hassan et al., 1999).

\section{Antidepressant effects on monoaminergic systems}

The mechanisms underlying the effects of long-term amitriptyline on water maze learning remain to be fully elucidated. The process may be glucocorticoid-mediated, or it may occur via the NE or the 5-HT system or a combination of several of these systems. Reversal learning slows down with age, a change related to age-associated changes in monoaminergic systems (Tanaka et al., 1992). Activation of the NE system in the basolateral amygdala appears to be an essential step in mediating glucocorticoid effects on memory storage (Quirarte et al., 1997) and in inducing glucocorticoid-mediated plasticity in the hippocampus. This suggests that successful long-term antidepressant therapy regimes may require more recruitment of NE-related systems. This contention is supported by recent preliminary findings that long-term treatment with desipramine (a selective NE-reuptake inhibitor) may also eliminate the emergence of cognitive deficits in a cohort of aged rats (Rowe et al., 1998), whereas venlafaxine, which has a greater potency for 5-HT reuptake than NE reuptake (Beique et al., 1998; Redrobe et al., 1998), had no significant effect on spatial learning in aged rats (Yau and Seckl, unpublished observations). Amitriptyline, in contrast, is approximately equally active as an inhibitor of 5-HT reuptake and NE reuptake (Meltzer and Lowy, 1997).

\section{Anxiolytic effects of amitriptyline}

Differences in anxiety-related behaviors could have a secondary effect on the rate of learning (reflecting an effect akin to pseudodementia in humans). Increased fearfulness or sensorimotor disturbances may cause performance impairments in the water maze that can sometimes be misinterpreted as spatial memory deficits (Miyakawa et al., 1996; Cain, 1997). Pretraining of animals in the water maze has been shown to reduce the general (nonspatial) aspects of solving the task (Cain, 1997). In the present study, the extensive training given (twice tested in water maze) most likely would have reduced the nonspatial aspect of learning the water maze task by the stage when all rats were finally retested. Furthermore, the aged cognitively impaired rats had swim speeds and thigmotaxic behavior (indicative of fearfulness) that were not significantly different from those of the aged cognitively unimpaired rats. Thus, the learning impairments found in this subgroup of aged controls apparently does not reflect merely sensorimotor deficits or heightened anxiety and is most likely caused by spatial memory deficits. Amitriptyline treatment significantly reduced anxiety-like measures in the aged rats, consistent with other reports showing anxiolytic effects of antidepressants (Kurt et al., 2000). The effects of amitriptyline on the affective state of the animal, together with the reduced evening corticosterone level, may therefore contribute to the improved cognitive function in the aged rat. Interestingly, the time spent in the open arms of the elevated plus-maze has been shown to correlate negatively with poststress corticosterone levels in rats (Vallee et al., 1997). The underlying mechanism whereby chronic 
amitriptyline treatment improves anxiety in aged rats is unclear but may be related to changes in $\mathrm{CRH}$ expression in the central amygdala. Central or intra-amygdaloid administration of CRH is anxiogenic (Dunn and Berridge, 1990), whereas the administration of $\mathrm{CRH}$ antagonists has anxiolytic activity (Britton et al., 1986). Furthermore, CRH mRNA expression has been shown to be decreased in the paraventricular nucleus of the hypothalamus after treatment with the tricyclic antidepressant imipramine in rats (Brady et al., 1991).

Chronically elevated glucocorticoid levels appear to cause hippocampal-dependent memory impairments in aged rats and humans (Seckl and Olsson, 1995; Lupien et al., 1998). Hence, the chronically lowered plasma corticosterone levels after amitriptyline administration may, at least in part, reduce the emergence of cognitive impairments with aging. Other effects of amitriptyline may also contribute to the preserved learning in the aged rats. For example, its serotonergic actions via postsynaptic 5-HT receptors expressed in limbic brain regions, such as the 5-HT6 receptor, which has been implicated recently in learning and memory (Woolley et al., 2001), may add to the positive cognitive effects. Whether the binding density or affinity of the 5-HT6 receptors in the hippocampus are altered by the chronic amitriptyline treatment in the aged rats remains to be determined. Changes in synaptic plasticity of hippocampal function are another possible effect of amitriptyline. Age-related defects in spatial memory have been associated with impaired hippocampal long-term potentiation, and this can be attenuated by drugs that enhance the cAMP signaling pathway (Bach et al., 1999). Because chronic antidepressant treatment upregulates the cAMP cascade (Thome et al., 2000), alterations in synaptic plasticity in the amitriptylinetreated aged rats may also contribute to preserving cognitive function. Although additional work is necessary to unravel the mechanisms underlying the beneficial effects of chronic amitriptyline on cognitive function with aging, perhaps long-term treatment with antidepressant drugs that reduce circulating glucocorticoid levels may represent a novel and potentially useful therapeutic approach in preventing the emergence of cognitive deficits among an aging human population.

\section{REFERENCES}

Al Dujaili EAS, Williams BC, Edwards CRW (1981) The development and application of a direct radioimmunoassay for corticosterone. Steroids 37:157-176.

Bach ME, Barad M, Son H, Zhuo M, Lu YF, Shih R, Mansuy I, Hawkins RD, Kandel ER (1999) Age-related defects in spatial memory are correlated with defects in the late phase of hippocampal long-term potentiation in vitro and are attenuated by drugs that enhance the cAMP signaling pathway. Proc Natl Acad Sci USA 96:5280-5285.

Beique JC, deMontigny C, Blier P, Debonnel G (1998) Blockade of 5-hydroxytryptamine and noradrenaline uptake by venlafaxine: a comparative study with paroxetine and desipramine. $\mathrm{Br} \mathrm{J}$ Pharmacol 125:526-532.

Bodnoff SR, Humphreys AG, Lehman JC, Diamond DM, Rose GM, Meaney MJ (1995) Enduring effects of chronic corticosterone treatment on spatial learning, synaptic plasticity, and hippocampal neuropathology in young and mid-aged rats. J Neurosci 15:61-69.

Brady LS, Whitfield Jr HJ, Fox RJ, Gold PW, Herkenham M (1991) Long-term antidepressant administration alters corticotropin-releasing hormone, tyrosine hydroxylase and mineralocorticoid receptor gene expression in the rat brain. J Clin Invest 87:831-837.

Britton KT, Lee G, Vale W, Rivier J, Koob GF (1986) Corticotropin releasing factor (CRF) receptor antagonist blocks activating and "anxiogenic" actions of CRF in the rat. Brain Res 369:303-306.

Cain DP (1997) Prior non-spatial pretraining eliminates sensorimotor disturbances and impairments in water maze learning caused by diazepam. Psychopharmacology (Berl) 130:313-319.

Carnes M, Lent SJ, Feyzi J, Hazel D (1989) Immunoneutralization of CRH prevents the diurnal surge of ACTH. Life Sci 45:1045-1056.

Carnes M, Lent SJ, Goodman B, Mueller C, Saydoff J, Erisman S (1990) Effects of immunoneutralization of corticotropin-releasing hormone on ultradian rhythms of plasma adrenocorticotropin. Endocrinology 126:1904-1913.

Dallman MF, Akana SF, Cascio CS, Darlington DN, Jacobson L, Levin N (1987) Regulation of ACTH secretion: variations on a theme of B. Recent Prog Horm Res 43:113-173.

De Kloet ER (1991) Brain corticosteroid receptor balance and homeostatic control. Front Neuroendocrinol 12:95-164.

Diamond DM, Bennett MC, Fleshner M, Rose GM (1992) Inverted-U relationship between the level of peripheral corticosterone and the magnitude of hippocampal primed burst potentiation. Hippocampus 2:421-430.

Dunn AJ, Berridge CW (1990) Physiological and behavioral responses to corticotropin-releasing factor administration: is CRF a mediator of anxiety or stress responses? Brain Res Brain Res Rev 15:71-100.

Gallagher M, Burwell R, Burchinal M (1993) Severity of spatial learning impairment in aging: development of a learning index for performance in the Morris water maze. Behav Neurosci 107:618-626.

Hassan AH, Patchev VK, von Rosenstiel P, Holsboer F, Almeida OF (1999) Plasticity of hippocampal corticosteroid receptors during aging in the rat. FASEB J 13:115-122.

Holsboer F, Barden N (1996) Antidepressants and hypothalamicpituitary-adrenocortical regulation. Endocr Rev 17:187-205.

Issa AM, Rowe W, Gauthier S, Meaney MJ (1990) Hypothalamicpituitary-adrenal activity in aged, cognitively impaired, and cognitively unimpaired rats. J Neurosci 10:3247-3254.

Jacobson L, Sapolsky R (1991) The role of the hippocampus in feedback regulation of the hypothalamic-pituitary-adrenal axis. Endocr Rev 12:118-134.

Kurt M, Arik AC, Celik S (2000) The effects of sertraline and fluoxetine on anxiety in the elevated plus-maze test in mice. J Basic Clin Physiol Pharmacol 11:173-180.

Landfield PW, Baskin RK, Pitler TA (1981) Brain aging correlates: retardation by hormonal-pharmacological treatments. Science 214:581-584.

Lupien SJ, de Leon M, de Santi S, Convit A, Tarshish C, Nair NPV, Thakur M, McEwen BS, Hauger RL, Meaney MJ (1998) Cortiso levels during human aging predict hippocampal atrophy and memory deficits. Nat Neurosci 1:69-73.

Meaney MJ, Aitken DH, van Berkel C, Bhatnagar S, Sapolsky RM (1988) Effect of neonatal handling on age-related impairments associated with the hippocampus. Science 239:766-768.

Meaney MJ, Aitken DH, Viau V, Sharma S, Sarrieau A (1989) Neonatal handling alters adrenocortical negative feedback sensitivity and hippocampal type II glucocorticoid receptor binding in the rat. Neuroendocrinology 50:597-604.

Meltzer HY, Lowy MT (1987) The serotonin hypothesis of depression. In: Psychopharmacology: the third generation of progress (Meltzer HY, ed), pp 513-526. New York: Raven.

Miyakawa T, Yagi T, Kagiyama A, Niki H (1996) Radial maze performance, open-field and elevated plus-maze behaviors in Fyn-kinase deficient mice: further evidence for increased fearfulness. Brain Res Mol Brain Res 37:145-150.

Oitzl MS, de Kloet ER (1992) Selective corticosteroid antagonists modulate specific aspects of spatial orientation learning. Behav Neurosci 106:62-71.

Pavlides C, Watanabe Y, McEwen BS (1993) Effects of glucocorticoids on hippocampal long-term potentiation. Hippocampus 3:183-192.

Quirarte GL, Roozendaal B, McGaugh JL (1997) Glucocorticoid enhancement of memory storage involves noradrenergic activation in the basolateral amygdala. Proc Natl Acad Sci USA 94:14048-14053.

Redrobe JP, Bourin M, Colombel MC, Baker GB (1998) Dosedependent noradrenergic and serotonergic properties of venlafaxine in animal models indicative of antidepressant activity. Psychopharmacology 138:1-8.

Reul JMHM, Stec I, Söder M, Holsboer F (1993) Chronic treatment of rats with the antidepressant amitriptyline attenuates the activity of the hypothalamic-pituitary-adrenocortical system. Endocrinology 133:312-320.

Reul JMHM, Labeur MS, Grigoriadis DE, De Souza EB, Holsboer F (1994) Hypothalamic-pituitary-adrenocortical axis changes in the rat after long-term treatment with the reversible monoamine oxidase-A inhibitor moclobemide. Neuroendocrinology 60:509-519.

Rothuizen J, Reul JM, van Sluijs FJ, Mol JA, Rijnberk A, de Kloet ER (1993) Increased neuroendocrine reactivity and decreased brain mineralocorticoid receptor-binding capacity in aged dogs. Endocrinology 132:161-168.

Rowe W, Steverman A, Walker M, Sharma S, Barden N, Seckl JR, Meaney MJ (1997) Antidepressants restore hypothalamic-pituitaryadrenal feedback function in aged, cognitively-impaired rats. Neurobiol Aging 18:527-533.

Rowe W, Sharma S, Yau J, Seckl JR, Quirion R, Rose GM, Meaney MJ (1998) Hypothalamic-pituitary-adrenal axis hyperactivity in mid-aged rats predicts cognitive deficits in later life which are attenuated by chronic antidepressant treatment. Soc Neurosci Abstr 24:1376.

Sandi C, Loscertales M, Guanza C (1997) Experience-dependent facil- 
itating effect of corticosterone on spatial memory formation in the water maze. Eur J Neurosci 9:637-642.

Sapolsky RM (1996) Stress, glucocorticoids, and damage to the nervous system: the current state of confusion. Stress 1:1-19.

Seckl JR, Fink G (1992) Antidepressants increase glucocorticoid and mineralocorticoid receptor mRNA expression in the rat hippocampus in vivo. Neuroendocrinology 55:621-626.

Seckl JR, Olsson T (1995) Glucocorticoids and the age-impaired hippocampus: cause or effect? J Endocrinol 145:201-211.

Seckl JR, Yau JLW, Holmes MC (1998) Glucocorticoids, serotonin and their interactions in the hippocampus. Amsterdam: Harwood Academic.

Tanaka J, Hori K, Nomura M (1992) Age-related changes in extracellular monoamine concentrations in the rat amygdala during a reversallearning task. J Neurochem 59:S27.

Thome J, Sakai N, Shin K, Steffen C, Zhang YJ, Impey S, Storm D, Duman RS (2000) cAMP response element-mediated gene transcrip- tion is upregulated by chronic antidepressant treatment. J Neurosci 20:4030-4036.

Vallee M, Mayo W, Dellu F, Le Moal M, Simon H, Maccari S (1997) Prenatal stress induces high anxiety and postnatal handling induces low anxiety in adult offspring: correlation with stress-induced corticosterone secretion. J Neurosci 17:2626-2636.

van Eekelen JA, Rots NY, Sutanto W, Oitzl MS, de Kloet ER (1991) Brain corticosteroid receptor gene expression and neuroendocrine dynamics during aging. J Steroid Biochem Mol Biol 40:679-683.

Woolley ML, Bentley JC, Sleight AJ, Marsden CA, Fone KC (2001) A role for 5-HT6 receptors in retention of spatial learning in the Morris water maze. Neuropharmacology 41:210-219.

Yau JLW, Olsson T, Morris RGM, Meaney MJ, Seckl JR (1995) Glucocorticoids, hippocampal corticosteroid receptor gene expression and antidepressant treatment: relationship with spatial learning in young and aged rats. Neuroscience 66:571-581. 